\title{
Notas sobre a formação territorial e dinâmica populacional dos municípios integrantes da APA do rio Machado - MG ${ }^{1}$
}

\section{Notes on the territorial formation and population dynamics of the municipalities integrated in the Environmental Protection Area (EPA) of Machado river, state of Minas Gerais}

Gil Carlos Silveira Porto Doutor em Geografia e docente do curso de Geografia da Universidade Federal de Alfenas - MG, Brasil porto.gil@gmail.com

Flamarion Dutra Alves Doutor em Geografia e docente do curso de Geografia da Universidade Federal de Alfenas - MG, Brasil dutrasm@yahoo.com.br

Daniel Hideki Bando Doutor em Ciências Médicas e docente do curso de Geografia da Universidade Federal de Alfenas - MG, Brasil danhideki@gmail.com

Tiago Marini Ribeiro Discente do curso de Geografia Licenciatura da Universidade Federal de Alfenas - MG, Brasil

tiago.mariniribeiro@yahoo.com.br

Matheus de Oliveira Silva Discente do curso de Geografia Bacharelado da Universidade Federal de Alfenas - MG, Brasil matheus-sjc@hotmail.com.br

\section{Resumo}

Este escrito resulta de estudo sociodemográfico em bacias hidrográficas. Buscou-se evidenciar o processo de formação espacial dos municípios que integram a Área de Proteção Ambiental (APA) do rio Machado e descrever aspectos da dinâmica populacional passada e atual. A pesquisa mostrou a importância da migração estrangeira na dinâmica demográfica pretérita e revelou características atuais da população, como a alta expectativa de vida e taxa de fecundidade abaixo do nível de reposição. As informações foram obtidas por meio da coleta e análise de dados secundários e realização de trabalho de campo.

Palavras-chaves: formação territorial, APA do rio Machado, indicadores sociodemográficos.

\footnotetext{
${ }^{1}$ NOTA DOS AUTORES

O presente artigo fará parte de livro que comporá o Relatório Final do Projeto "Diagnóstico Geoambiental da APA da bacia hidrográfica do rio Machado/MG", produto de trabalho desenvolvido por docentes do curso de Geografia e Ciências Biológicas (Bacharelado e Licenciatura) da Unifal-MG, em parceria com a ARPA e o IEF. Os artigos destinam-se ao público acadêmico, enquanto o Relatório às autoridades municipais, judiciais e à população local.
} 


\begin{abstract}
This paper results from a socio-demographic study in watershed areas. It aims to evidence the process of spatial formation of the municipalities that integrate the Environmental Protection Area (EPA) of the Machado river and to describe aspects of the past and current population dynamics. The research showed the importance of foreign migration in the past demographic dynamics and presented current characteristics of the population, such as the high life expectancy of the population and the presence of a fecundity rate below the replacement level, for example. The information was obtained through the collection and analysis of secondary data and the accomplishment of field work.
\end{abstract}

Keywords: territorial formation, Machado River EPA, socio-demographic indicators.

\title{
1. INTRODUÇÃO
}

A análise apresentada nas linhas que se seguem resulta de uma investigação da realidade, que tem por finalidade contribuir com o entendimento do processo de formação territorial dos municípios que integram a APA, considerando o papel da dinâmica populacional pretérita e atual. Identificou-se diferentes aspectos dos municípios nos quais a APA está inserida, dentre esses, menciona-se características demográficas como a população absoluta, sua divisão por faixa etária, gênero, dentre outros aspectos. As unidades municipais, bem como a delimitação da área protegida, estão representadas na Figura 1.

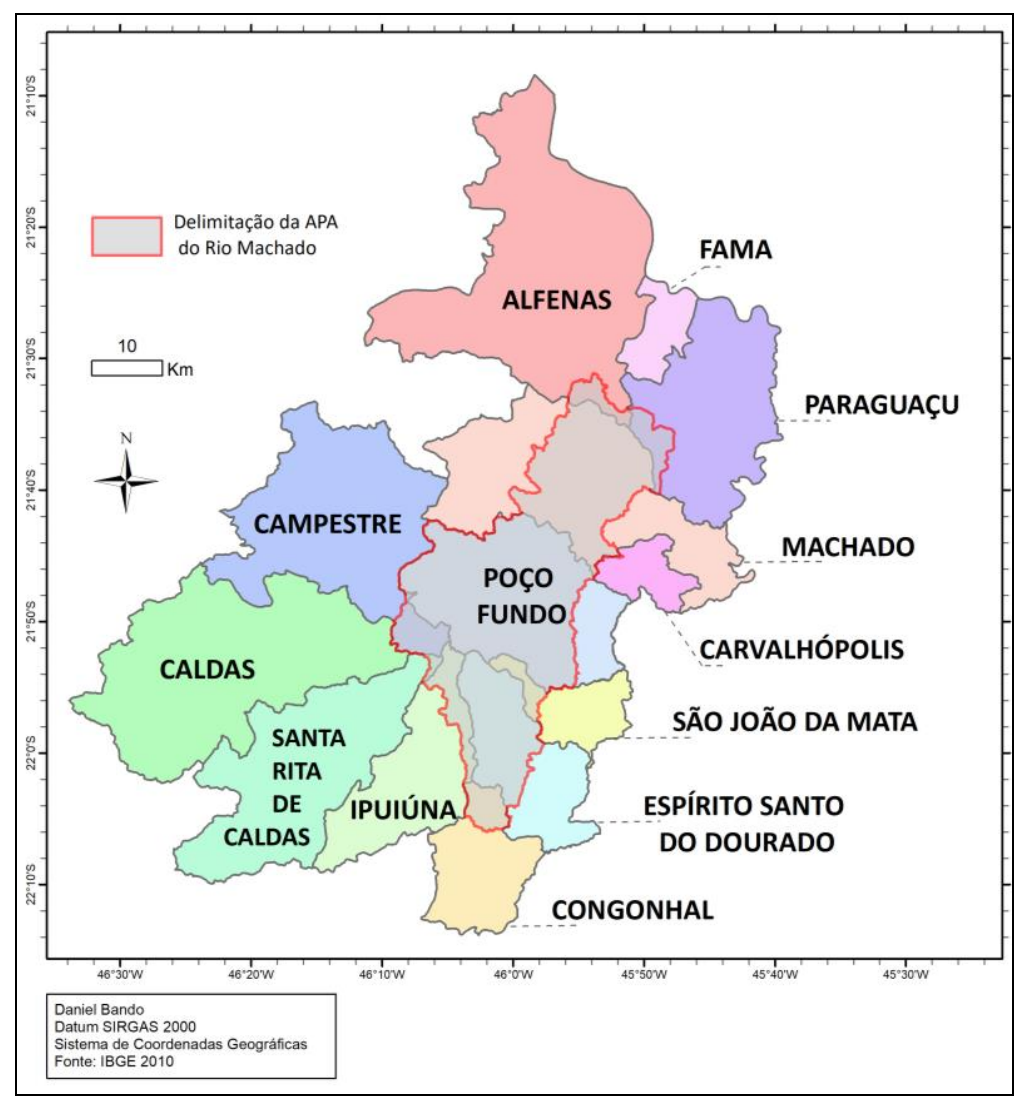

Figura 1 - APA do Rio Machado e municípios que a integram.

Fonte: IBGE, 2010; BANDO, 2019. 
A observação da Figura 1 possibilita afirmar que a área da bacia se insere, sobretudo, nos territórios municipais de Machado, Poço Fundo e Espírito Santo do Dourado, fato que nos levou a analisar a dinâmica populacional desses municípios com maior atenção, embora a análise da totalidade dos dados tenha permeado toda a pesquisa.

A análise social de uma área correspondente a uma bacia hidrográfica e, por sua vez, a uma área de proteção ambiental, se constitui num desafio para os geógrafos humanos, uma vez que o limite da área drenada não corresponde às fronteiras das unidades municipais. Desse modo, a escala selecionada para estudo, coleta e análise de dados foi a que corresponde aos municípios anteriormente citados, considerando que a formação socioespacial e as características populacionais ali presentes se mantêm nas áreas drenadas pelos rios que formam a bacia hidrográfica do rio Machado. Após definição desse critério, a pesquisa foi dividida em três etapas.

A primeira abarcou a coleta de dados no Instituto Brasileiro de Geografia e Estatística (IBGE), nas plataformas SIDRA e IBGE CIDADES, além de buscas no site Atlas Brasil, Fundação João Pinheiro (FJP) e Instituto de Pesquisa Econômica Aplicada (IPEA). As informações são oriundas dos censos agropecuários (2006) e demográfico (2010) do IBGE e abarcam desde a distribuição da população residente nas áreas rurais e urbanas, passando pela distribuição por faixa etária, bem como abarcando o Produto Interno Bruto (PIB) de cada unidade municipal, por exemplo. Também foram realizadas pesquisas em livros, monografias, teses e artigos acadêmicos objetivando encontrar vestígios do processo de ocupação e povoamento da área em questão.

O agrupamento das informações de cada município em tabelas e gráficos foi feito na segunda etapa da pesquisa, possibilitando identificar características gerais da população residente, bem como especificidades populacionais que possuem.

Num terceiro momento da pesquisa, realizou-se trabalho de campo, objetivando observar elementos da paisagem percorrida, bem como situações que contribuíssem para caracterizar o modo de vida da população residente na área da APA. ${ }^{2} \mathrm{O}$ trabalho de campo também possibilitou a realização de entrevistas abertas, com intuito de conhecer melhor as trajetórias de vida dos moradores residentes na bacia do rio Machado, sua composição familiar, renda, origem dos alimentos que consome, problemas enfrentados, as atividades culturais e sua organização social, bem como a percepção que possuem dos rios por eles utilizados, ou seja, essa etapa objetivou conhecer melhor a população, e sua relação com os rios e o lugar.

2 Foram realizados dois trabalhos de campo: o primeiro ocorreu em 21 de fevereiro de 2018, onde se realizou 7 (sete) entrevistas em bairros rurais dos municípios de Poço Fundo e Ipuiúna, na tentativa de entender a importância e uso do rio junto aos agricultores familiares; o segundo ocorreu no dia 07 de maio do mesmo ano e percorreu os bairros do Centro, Santo Antônio 1 e Córrego Fundo no município de Machado. Nessa última oportunidade, foram realizadas 14 (quatorze) entrevistas, e a escolha desses bairros se deu pela ocupação urbana junto ao leito do rio Machado e seus afluentes. 


\section{ASPECTOS DA FORMAÇÃO TERRITORIAL E QUADRO REGIONAL ATUAL}

O processo de povoamento dos municípios em estudo é antigo e se amplia de maneira semelhante ao ocorrido no Sul de Minas, quando este fortalece os laços de troca com importantes cidades brasileiras, como Rio de Janeiro, São Paulo e Belo Horizonte, ainda que tardiamente com essa última. Com a ampliação das atividades econômicas regionais, bem como da população, novos municípios foram criados, atendendo, por um lado, às elites agrárias locais e, por outro, ao Estado, que desejava fortalecer suas influências no modo de vida das localidades em expansão.

Como se observa na Tabela 1, que mostra o ano de formação territorial dos municípios que compõem a APA, Caldas é o município mais antigo (1849) e se localiza no Sudoeste da APA; sua ocupação se deu pelo início e fortalecimento da agropecuária e se iniciou por volta de 1780, e sua criação se deu numa primeira fase de criação de municípios no Sul Mineiro.

Tabela 1 - Ano de instalação dos municípios da APA do

\begin{tabular}{l|c}
\multicolumn{2}{c}{ Rio Machado, no ano de 2010 } \\
\hline Municípios & Ano de Instalação \\
\hline Caldas & 1849 \\
Alfenas & 1860 \\
Machado & 1880 \\
Campestre & 1911 \\
Paraguaçu & 1911 \\
Poço Fundo & 1923 \\
Santa Rita de Caldas & 1943 \\
Fama & 1948 \\
Ipuíuna & 1953 \\
Congonhal & 1953 \\
Carvalhópolis & 1953 \\
São João da Mata & 1962 \\
Espírito Sto. Dourado & 1962 \\
\hline
\end{tabular}

Fonte: PNUD, Ipea, FJP.

Para Gambi et al. (2012), um segundo período de criação de unidades municipais ocorreu entre 1860-1880, com a criação de Alfenas e Machado. No caso de Alfenas, localizada no norte da APA, há registro das primeiras ocupações desde 1805, ano em que terreno foi doado para a construção da Capela de Nossa Senhora das Dores e São José, situada hoje na praça central da cidade, denominada Getúlio Vargas. Outros dois municípios foram emancipados na década de 1910; outros ainda na década de 1940; e um grupo maior (cinco municípios), criados entre 1953 e 1962, sendo que, nesse último ano, os municípios de São João da Mata e Espírito Santo do Dourado foram instalados.

A dinâmica socioespacial acima apresentada foi reflexo e condição do avanço das relações capitalistas de produção, cujos agentes e ideias que o conceberam originavam-se, sobretudo, de outras centralidades comerciais e econômicas da época, como São Paulo e Rio de Janeiro, essa 
última capital da República, mas também de regiões situadas na Europa e Estados Unidos, que demandavam do Sul de Minas o café, denominado por alguns historiadores e memorialistas como o ouro verde. Cabe também ressaltar o papel da sociedade local, enraizada nessa região desde séculos passados, que tinha como centralidade da vida cotidiana o campo e a realização da agricultura de subsistência, como a que abastecia a corte.

$\mathrm{Na}$ sequência serão apresentados aspectos formadores do Sul de Minas no que tange às questões acima levantadas, enfatizando, ainda, de forma resumida, o abastecimento para a coroa, a expansão cafeeira e a chegada dos trilhos.

Antes da efervescência do café no Sul de Minas, desenvolviam-se ali atividades produtivas de abastecimento à própria região e ao mercado consumidor da antiga capital do Império e depois da República. De acordo com Saes e Castilho (2016, p. 94) “[...] ao longo do século XIX, a região se consolidou como um dos mais importantes centros de produção de gêneros de abastecimento do país, atendendo especialmente à Corte no Rio de Janeiro", constituindo-se num espaço tradicional no cultivo de arroz, milho, feijão e outros produtos. De acordo com Veiga (1885 apud SAES; CASTILHO, 2016), os principais produtos exportados, por exemplo, pela freguesia de Alfenas eram o milho e a cana-de-açúcar, que se equiparava à criação de gado bovino e suíno.

Não se sabe ao certo se o café plantado nessa área de Minas Gerais, na segunda metade dos Oitocentos, resultou da expansão da cafeicultura de São Paulo ou resultou da crise cafeeira que assolou os produtores da Zona da Mata. Ainda de acordo com Saes e Castilho (2016), independentemente de onde chegaram as primeiras mudas da planta, há um consenso que, somente na década de 1880, a produção se destacaria no grupo de itens exportados pela Província de Minas Gerais como um todo. ${ }^{3}$ Para eles,

[...] o café, nas duas últimas décadas do século XX, tomou a paisagem do sul de Minas, não sendo apenas uma cultura entre outras, um produto acessório para apoiar a renda agrícola familiar, mas uma atividade que ampliava substancialmente sua participação entre os produtos especializados da reunião (p. 95).

O crescimento da cafeicultura em Alfenas e Machado, e nos seus arredores, não apenas impulsionou o crescimento da população, mas também contribuiu para o crescimento de atividades urbanas, como a ampliação do comércio, a chegada de bancos, a construção de pequenas unidades fabris e uma maior participação da elite econômica na política estadual.

Outro aspecto que mudou sensivelmente a dinâmica social e econômica dos municípios que integram a APA do rio Machado foi a chegada da ferrovia no final do século XIX e nas

3 A freguesia de Machado na década de 1870 já exportava café para São Paulo e Rio de Janeiro (RABELO, 2006 apud SAES CASTILHO, 2016); 
primeiras décadas do século XX. Das sedes municipais que fazem parte dos municípios drenados pelo rio Machado e seus afluentes, três passaram a integrar nós da rede ferroviária regional e nacional. Nos referimos a Fama, Alfenas e Machado, que estavam articuladas à Estrada de Ferro Muzambinho, que conectava as cidades de Três Pontas a Guaxupé. Machado foi conectada à estação de Gaspar Lopes (no município de Alfenas) em 1928 e essa, por sua vez, foi articulada à linha de Muzambinho em 1897. A Estrada de Ferro Muzambinho (criada em 1892) foi incorporada, em 1908, pela Estrada de Ferro Minas-Rio (DAVI, 2017). Um aspecto importante no processo de construção do ramal ferroviário que ligou Machado a Gaspar Lopes foi a participação de acionistas locais, sendo dois deles importantes produtores de café no município. Em termos gerais, os cafeicultores reduziram os custos com o transporte do café, que antes eram transportados por carros de boi (MARTINS, 2016).

\subsection{Contexto atual}

Aspecto importante a ser considerado no estudo de áreas ambientalmente protegidas é o atual nível de urbanização dos municípios que a integram e o grau de interação entre suas cidades. A presença de uma cidade de forte centralidade em relação àquelas da vizinhança pode indicar maior demanda por recursos naturais, logo maior degradação do solo, da cobertura vegetal e dos recursos hídricos. Considerando o estudo Região de Influência das Cidades - REGIC (2007), produzido pelo IBGE, que mapeia a área de influência de cidades brasileiras e a hierarquização entre elas, identificou-se o seguinte contexto dos municípios que integram a APA do rio Machado, que será descrito na sequência.

As unidades municipais em questão estão sob influência de Pouso Alegre, Poços de Caldas (essas duas não se localizam na área da APA) e Alfenas, cidades que sofrem influência direta da grande metrópole nacional, São Paulo. As unidades municipais dependentes de Pouso Alegre são Congonhal, Ipuiúna, Espírito Santo do Dourado e São João da Mata. Novamente, Ipuiúna, e as cidades de Caldas, Campestre e Santa Rita de Caldas estão sob influência de Poços de Caldas, considerada Centro Sub-Regional A. Alfenas, centralidade de maior peso na bacia hidrográfica em foco, mantém função de comando com relação aos municípios de Fama, Paraguaçu, Machado, Poço Fundo e Carvalhópolis.

Considerando o papel de cada município da área de estudo e suas respectivas cidades, na rede urbana sub-regional, a maioria das localidades são centros locais, à exceção de Machado que, ao lado de Alfenas, oferece serviços consumidos pela população local e pelos moradores de Poço Fundo e Carvalhópolis; enquanto Machado é considerada na rede urbana sub-regional como Centro de Zona B, Alfenas ocupa posição de Centro Sub-Regional A (REGIC - IBGE, 2007). A situação 
de centralidade geográfica e econômica dessas duas localidades, sobretudo de Alfenas, sugere que a área norte da APA esteja passando por um maior processo de degradação ambiental, demandando, assim, maior atenção dos gestores do território e implementação de políticas ambientais.

\section{ASPECTOS SOCIODEMOGRÁFICOS}

Para Damiani (2006), a Demografia contribuiu nos procedimentos de quantificação de dados e oferece material estatístico de cunho mais qualitativo para o entendimento da relação entre economia, população e espaço. Assim, coopera para que a geografia análise com maior profundidade causas e efeitos dos elementos da dinâmica demográfica (natalidade, mortalidade e migração) em cada recorte espacial. Para ela, o geógrafo, com base na Demografia, pode discorrer sobre a distribuição dos grupos humanos e da sociedade no espaço e como ela se apropria dos recursos existentes.

\subsection{Dinâmica populacional pretérita}

Nesse sentido, antes de discorrer sobre o quadro atual da população da APA do rio Machado, cabe apresentar algumas características da dinâmica demográfica histórica do Sul de Minas, que foi sendo produzida em sua relação com a utilização dos recursos naturais. De acordo com Saes e Castilho (2016), essa área era a segunda região em maior número de escravos na província mineira. Outro aspecto também elucidado pelos autores foi a contribuição de imigrantes italianos, portugueses e espanhóis na composição demográfica regional, sobretudo, no final dos Oitocentos e nas primeiras duas décadas do século XX, que se fixaram, sobretudo, em localidades mineiras próximas à fronteira de São Paulo e em municípios que se destacavam na produção de café. No entanto, a chegada desses grupos migratórios não teve o mesmo peso na população total do estado, como ocorreu em São Paulo, embora o censo de 1920 tenha registrado a presença de 1.806 imigrantes internacionais no município de Monte Santo de Minas e 1.854 em São Sebastião do Paraíso, unidades municipais que possuíam, respectivamente, terceira e quarta maiores proporções de terra utilizadas para o plantio do café na região (SAES; CASTILHO, 2016).

No caso específico da chegada de imigrantes em municípios que se situam na APA, cabe ressaltar a contribuição deles na expansão da atividade cafeeira em Machado, registrada ali desde 1874 (VEIGA, 1874 apud MARTINS, 2016). Com a assinatura da Lei Áurea (1888), os fazendeiros machadenses tiveram de encontrar novas formas de contratação de trabalhadores para o cultivo do café. Além de empregar trabalhadores livres nacionais, "os cafeicultores do município aderiram maciçamente ao programa de imigração promovido pelo governo de Minas Gerais” (COSTA, 2002, 
apud MARTINS, 2016, p. 148). Desse modo, Machado foi à localidade sul-mineira que mais atraiu trabalhadores estrangeiros (predominantemente italianos) ${ }^{4}$ entre 1895 e 1898 (MARTINS, 2016). Ainda de acordo com Martins, o avanço da cafeicultura contribuiu para o aumento da população de Santo Antônio do Machado, que teve sua emancipação política em 1880. "No ano de 1872, o Censo Geral do Império registrou 6.440 habitantes em Machado; em 1920, a população do município havia subido para 29.357 habitantes" (p. 149).

Cabe ressaltar que o crescimento populacional ocorreu em toda a região sul-minera no período acima citado. O número de habitantes dessa região pulou de 260 mil habitantes em 1872 e chegou a aproximadamente 730 mil em 1907, sendo que, no censo de 1920, registrou-se um contingente populacional de mais de 1 milhão de pessoas. Toda essa dinâmica demográfica fez com que se ampliasse os números de cidades na região, de 17 (em 1874), passando para 35 (em 1907) e chegando a quase 50 (em 1920) (MARTINS, 2016, p. 192). Das unidades municipais drenadas pelo rio Machado, 4 (quatro) foram criadas nesse período, conforme se observa na Tabela 1.

\subsection{Dinâmica populacional atual}

Os dados demográficos dos recortes municipais onde se distribuem os cursos d'água do rio Machado serviram para conhecer a realidade social e econômica sub-regional, visando identificar fragilidades e potencialidades da área. Inicialmente, foram escolhidas três variáveis que corroboraram ao entendimento dessa realidade; nos referimos à extensão territorial, à população residente e à densidade demográfica. Assim como escreveu Vidal de La Blache, no processo de apreciação da relação entre a Terra e os homens (e as mulheres), é relevante considerar a maneira como eles estão distribuídos na superfície terrestre (DAMIANI, 2006), e a densidade demográfica, embora insuficiente para estudar em profundidade a relação entre sociedade e espaço, é um quesito de peso a ser considerado na busca desse entendimento.

Dos municípios que compõem a APA, Alfenas, como mostra a Tabela 2, é o que apresenta maior extensão territorial em área $\left(850 \mathrm{~km}^{2}\right)$, população residente $(73.774)$ e uma densidade demográfica de $86,75 \mathrm{hab} / \mathrm{km}^{2}$. Essa primazia tem relação com inúmeros fatores, dentre eles, os quase 150 anos de emancipação política, a presença de duas universidades (Unifal-MG e Unifenas),

\footnotetext{
4 "Estes imigrantes italianos partiam do Porto de Gênova, em navios fretados pelo governo do estado de Minas Gerais, aportaram no Rio de Janeiro, onde foram alojados na hospedaria da Ilha das Flores. Daí eles foram encaminhados até Juiz de Fora, por meio da Estrada de Ferro Central do Brasil, sendo recebidos na sede da hospedaria Horta Barbosa. Depois, em um zigue-zague ferroviário, foram embarcados para a estação de Pontalete: de Juiz de Fora para o entroncamento da Central do Brasil com a "Minas \& Rio", em Cruzeiro (SP); de Cruzeiro até Três Corações na junção com a estrada de ferro de Muzambinho e, finalmente, de Três Corações a Pontalete, lugar situado no município de Três Pontas, ou Fama, então distrito de Alfenas. Finalmente, dessas estações os italianos seguiam de carroça para Machado" (MARTINS, 2016, p. 149).
} 
que são atrativos demográficos e para instalação de comércios e prestadores de serviço, bem como sua referência regional na área da saúde, pela oferta desse serviço a populações de outras unidades municipais. Assim, produz e movimenta fluxos econômicos, que se mostram um atrativo para a população dos municípios vizinhos procurarem, por exemplo, oportunidades de trabalho e emprego. A população dos não naturais em Alfenas, em 2010, era de 8.275 habitantes.

Tabela 2 - População, Área $\left(\mathrm{km}^{2}\right)$ e densidade demográfica (hab $\left./ \mathrm{km}^{2}\right)$ dos municípios da APA Rio do Machado, 2010

\begin{tabular}{l|c|c|c}
\hline Municípios & $\begin{array}{c}\text { População } \\
\text { Residente } \\
\mathbf{2 0 1 0}\end{array}$ & $\begin{array}{c}\text { Área } \\
\left.\mathbf{( k m}^{2}\right)\end{array}$ & $\begin{array}{c}\text { Densidade } \\
\text { Demográfica } \\
\mathbf{2 0 1 0} \\
\text { (hab/km } \mathbf{~})\end{array}$ \\
\hline Fama & 2.350 & 86,024 & 27,32 \\
\hline $\begin{array}{l}\text { São João da } \\
\text { Mata }\end{array}$ & 2.731 & 120,536 & 22,66 \\
Carvalhópolis & 3.341 & 81,101 & 41,20 \\
Espírito Sto. & 4.429 & 263,879 & 16,78 \\
do Dourado & & & \\
Santa Rita de & 9.027 & 503,011 & 17,95 \\
Caldas & & & \\
Ipuiúna & 9.521 & 298,195 & 31,93 \\
Congonhal & 10.468 & 205,125 & 51,03 \\
Caldas & 13.633 & 711,414 & 19,16 \\
Poço Fundo & 15.959 & 474,244 & 33,65 \\
Paraguaçu & 20.245 & 424,296 & 47,71 \\
Campestre & 20.686 & 577,843 & 35,80 \\
Machado & 38.688 & 585,958 & 66,03 \\
Alfenas & 73.774 & 850,446 & 86,75 \\
\hline
\end{tabular}

Carvalhópolis é o menor município em área $\left(81,101 \mathrm{~km}^{2}\right)$ e Fama possui a menor população (2.350 habitantes, em 2010). Já Espírito Santo do Dourado apresenta a menor densidade demográfica $\left(16,78 \mathrm{hab} / \mathrm{km}^{2}\right)$, pois tem uma área de $263,879 \mathrm{~km}^{2}$, considerada média em relação aos municípios da APA, e possui uma baixa população (4.429 habitantes), da qual 312 não são nasceram no município.

Em termos gerais, a análise da população absoluta das unidades municipais permite identificar 5 (cinco) grupos de municípios. Aquele que tem população até 10.000 habitantes (são seis municípios); o segundo grupo, que possui população entre 10 e 20 mil residentes (três estão nessa condição); são eles, Congonhal, Caldas e Poço Fundo. Paraguaçu e Campestre formam o terceiro grupo, Machado, sozinho o quarto e Alfenas, com mais de 70 mil habitantes, integra o último segmento. 


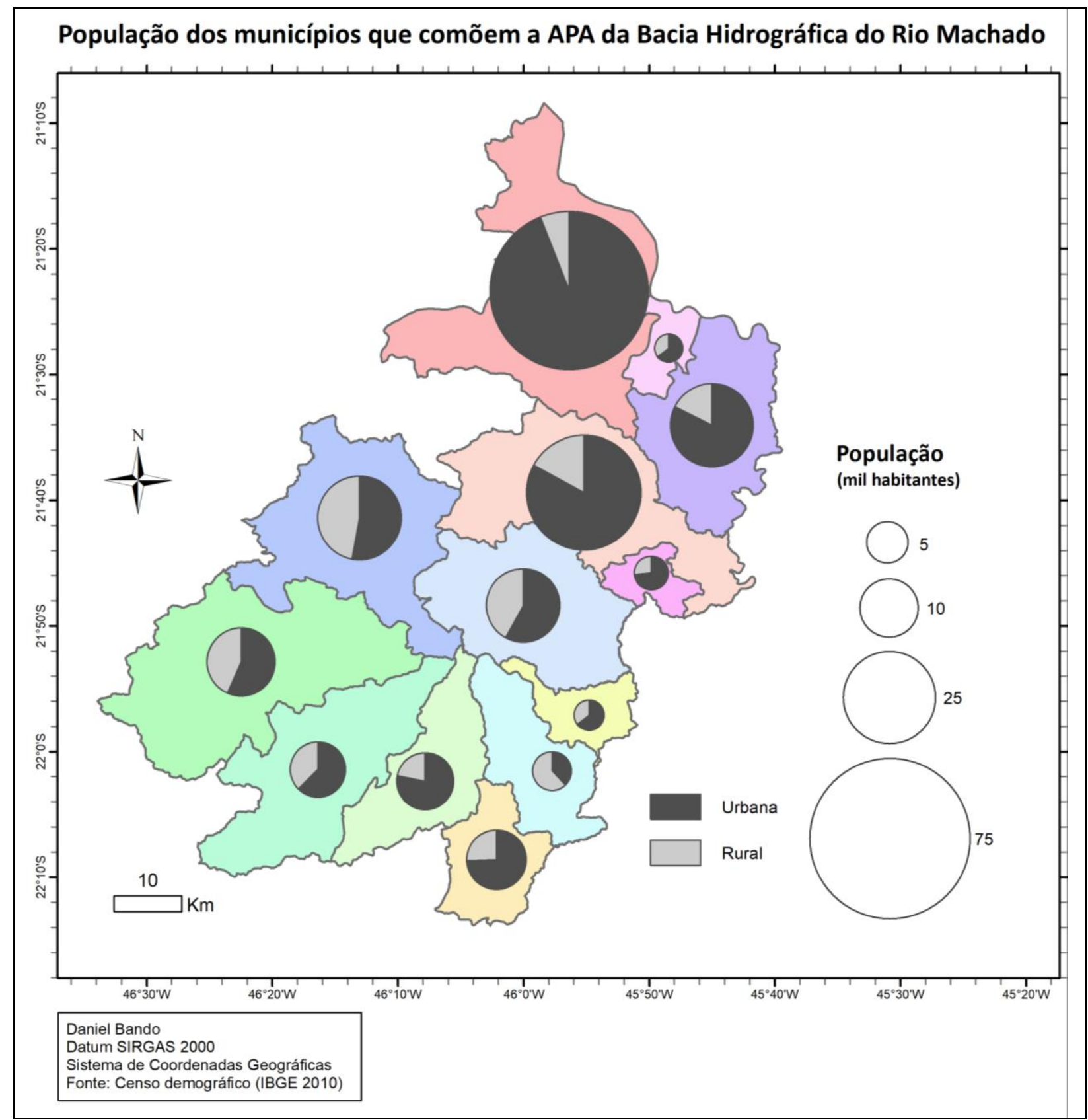

Figura 2 - População dos municípios que compõe a APA do Rio Machado, 2010.

Fonte: IBGE (2010); BANDO, 2019.

A observação da Figura 2 reforça o fenômeno da alta urbanização nos municípios em questão; em praticamente todos eles, a taxa de urbanização é bastante superior à de ruralização. Alfenas (94\%), Paraguaçu (82\%) e Machado (83\%) são as unidades municipais mais urbanizadas. Poço Fundo, Campestre e Caldas apresentam um equilíbrio entre população rural e urbana, com diferença menor que 20\%. O único município em que a população residente rural é maior que a urbana é Espírito Santo do Dourado, com 2.746 (62\%) moradores do campo, diferença de 15\% em relação à população urbana. Esse quadro talvez justifique o fato de haver ali uma predominância de homens em relação às mulheres, pois há possibilidade de haver maior demanda por mão de obra masculina, considerando as características agrária e cultural desse município. Grosso modo, pode se 
inferir que, nos municípios situados na APA do rio Machado, há alta interação entre o campo e a cidade, e que parte considerável da renda da população está ligada às atividades rurais. Cabe ressaltar que essa população se depara, muitas vezes, com a falta de serviços próximos de suas moradias, como aqueles oferecidos em escolas, postos de saúde ou hospitais, bem como estabelecimentos comerciais para aquisição de produtos para o consumo.

Os moradores do campo com os quais tivemos contato no trabalho de campo ${ }^{5}$ nasceram, cresceram, foram criados e construíram suas famílias nos locais de residência atual. Portanto, estabeleceram relação de afetividade com o lugar, pois ali trabalham e têm uma relação de pertencimento com a comunidade, aspectos que são considerados quando planejam migrar para as cidades em busca de trabalho, estudo, capacitação profissional e oportunidade de emprego. Nessa comunidade, os moradores utilizam, periodicamente, o espaço da igreja para realização de eventos sociais, bem como para discussão de problemas que envolvem a comunidade.

No que se refere à faixa etária da população desses municípios, por setor censitário, observou-se que, em termos relativos, Machado é a unidade municipal com maior porcentagem de habitantes com idade de 1 dia de vida até 14 anos, e que esse grupo reside sobretudo em setores rurais. Quanto à população com idade de 15 a 59 anos, observou-se que ela se concentra nas sedes municipais de Machado e Poço Fundo, bem como na parte sul da bacia, em áreas fronteiriças dos municípios de Ipuiúna, Santa Rita de Caldas, Caldas e Campestre. Já a população com idade superior a 59 se concentra no norte da bacia, na área correspondente ao município de Alfenas, nas porções oriental e ocidental do territorial fluvial de Poço Fundo e em setores urbanos das sedes municipais da APA.

Essa configuração se constitui importante dado no planejamento e execução de políticas públicas municipais ou elaboradas por outras instituições. Por exemplo, por um lado, essas poderiam ser voltadas à discussão e implantação de atividades voltadas à promoção de educação ambiental em localidades que estão na área mais setentrional da bacia, onde a porcentagem de crianças e adolescentes é maior.

Nessas áreas, como se observou na zona rural dos municípios de Poço Fundo, Ipuiúna e Espírito Santo do Dourado, há falta de escola próxima às casas dos moradores, o que cria dificuldades para as crianças e jovens estudarem. Quando chove as estradas de terra apresentam alto risco de atolamentos de automóveis, fazendo com que os alunos do campo não frequentem as escolas com assiduidade. Essa dificuldade pode provocar a desistência dos estudos. É o caso de uma das pessoas entrevistadas, cujas dificuldades acima apresentadas a fez desistir dos estudos.

\footnotetext{
5 Residentes no sítio Campinho, bairro rural de Tamanduá, em Ipuiúna, zona fronteiriça ao município de Poço Fundo.
} 
Por outro lado, um maior adensamento populacional de pessoas de 15 a 59 anos nas áreas urbanas demanda políticas voltadas à ampliação de oportunidades de trabalho e emprego e, ao mesmo tempo, ações indutoras de participação na gestão da sociedade local, tanto política como ambientalmente. Essa relação entre grupos etários distintos e suas necessidades mostra que estratos populacionais distintos (idade, classe social, gênero) produzem espacialidades diferentes.

Gráfico 1 - Composição de gêneros nos municípios da APA do Rio Machado, 2010

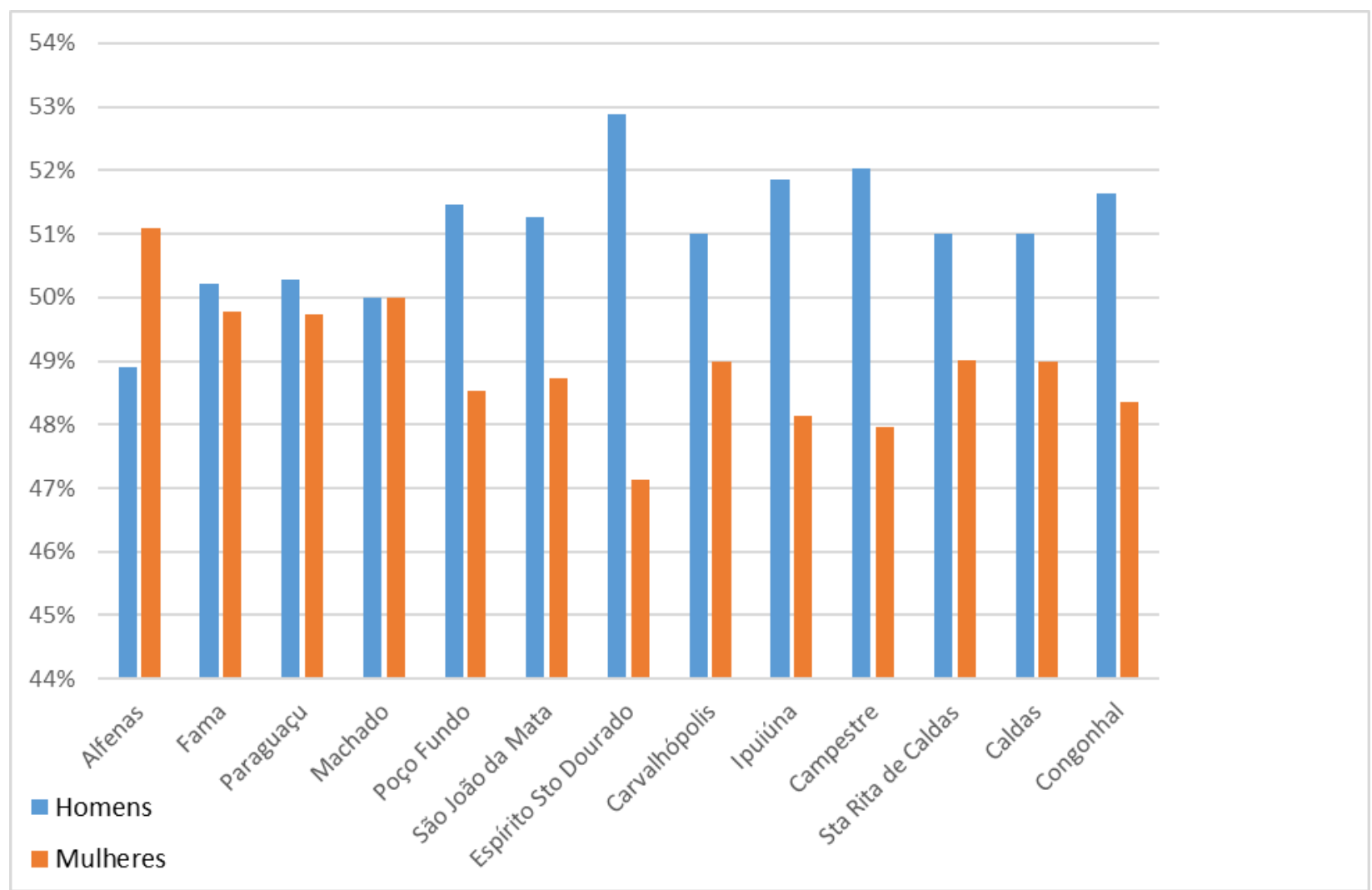

Fonte: IBGE, 2010.

Analisando a composição por gênero nos municípios da APA do Rio Machado, em apenas dois, Alfenas e Machado, o contingente de mulheres supera o de homens. Em Alfenas, essa diferença era mais notável em 2010, quando as mulheres totalizaram 37.693 (hab.), enquanto os homens chegaram a 36.081 (hab.). Já em Machado, as mulheres eram de 19.346 (hab.) e os homens 19.342. Nos demais municípios, como se observa no Gráfico 1, os homens são maioria; no entanto, a pequena diferença entre homens e mulheres não significa que há um problema no processo de reposição demográfica e essa diferença pode estar relacionada à emigração de um maior número de mulheres ou a uma maior imigração masculina. 
Tabela 3 - Indicadores populacionais dos municípios da APA do Rio Machado, 2010

\begin{tabular}{|c|c|c|c|c|c|c|}
\hline Municípios & IDHM & $\begin{array}{c}\text { IDHM } \\
\text { Educação }\end{array}$ & $\begin{array}{c}\text { IDHM } \\
\text { Longevidade }\end{array}$ & Longevidade & $\begin{array}{l}\text { Mortalidade } \\
\text { Infantil (\%o) }\end{array}$ & $\begin{array}{c}\text { Fecundidade } \\
\text { Total }\end{array}$ \\
\hline São João da Mata & 0,653 & 0,501 & 0,822 & 74,3 & 16,4 & 1,3 \\
\hline Esp. $\mathrm{St}^{\mathrm{o}}$ do Dourado & 0,685 & 0,576 & 0,847 & 75,8 & 14,1 & 1,4 \\
\hline Ipuiúna & 0,686 & 0,516 & 0,866 & 77 & 12,4 & 2,2 \\
\hline Caldas & 0,687 & 0,529 & 0,837 & 77,4 & 12,0 & 1,9 \\
\hline $\mathrm{St}^{\mathrm{a}}$ Rita de Caldas & 0,690 & 0,576 & 0,823 & 74,4 & 16,3 & 1,7 \\
\hline Poço Fundo & 0,691 & 0,541 & 0,866 & 77 & 12,5 & 2,0 \\
\hline Campestre & 0,698 & 0,566 & 0,843 & 75,6 & 14,4 & 2,1 \\
\hline Congonhal & 0,712 & 0,626 & 0,847 & 75,8 & 14,1 & 1,6 \\
\hline Paraguaçu & 0,715 & 0.623 & 0,850 & 76 & 13,9 & 1,8 \\
\hline Machado & 0,715 & 0,600 & 0,848 & 75,9 & 14,0 & 2,0 \\
\hline Fama & 0,717 & 0,610 & 0,863 & 76,8 & 12,7 & 1,9 \\
\hline Carvalhópolis & 0,724 & 0,648 & 0,850 & 76 & 13,9 & 2,0 \\
\hline Alfenas & 0,761 & 0,712 & 0,841 & 75,5 & 14,6 & 1,9 \\
\hline
\end{tabular}

Fonte: PNUD, Ipea, FJP, 2010.

No que se refere ao nível de desenvolvimento dos municípios, como se observa na Tabela 3, Alfenas é o único que tem o Índice de Desenvolvimento Humano Municipal (IDHM) (0,761) superior à média de Minas Gerais $(0,731)$ e superior à média brasileira (0,727) (IBGE, 2018). Os outros municípios da APA estão abaixo das médias estadual e nacional. Estes números baixos de desenvolvimento podem, ainda, sinalizar uma dificuldade da população destes municípios de acessarem adequadamente serviços de educação e saúde e possuírem renda que lhes assegure boa qualidade de vida. Chama a atenção no grupo dos municípios a posição de São João da Mata quanto aos indicadores em questão. Ele possui os menores índices de IDHM Educação, IDHM Longevidade e Taxa de Fecundidade Total (0,501, 0,822 e 1,3 em sequência); apresenta também a maior taxa de mortalidade infantil $(16,4)$ entre os municípios da APA. Em termos gerais, há uma relação entre taxa de urbanização e IDHM dos municípios, ou seja, a maioria das unidades mais urbanizadas apresentam também os melhores índices de desenvolvimento. Dos seis municípios que possuem IDHM superior a setecentos, cinco deles possuem as maiores taxas de urbanização: Alfenas, Machado, Paraguaçu, Carvalhópolis e Congonhal.

Em termos gerais, a população que reside na área de abrangência do rio Machado não apresenta grandes disparidades se comparamos os diferentes indicadores por município. No entanto, há algumas diferenças que precisam ser observadas no caso da implementação de uma gestão adequada na utilização dos recursos hídricos. A Figura 3 nos possibilita ter uma visão geral de alguns indicadores sub-regionais que podem ser utilizados para esse fim. 

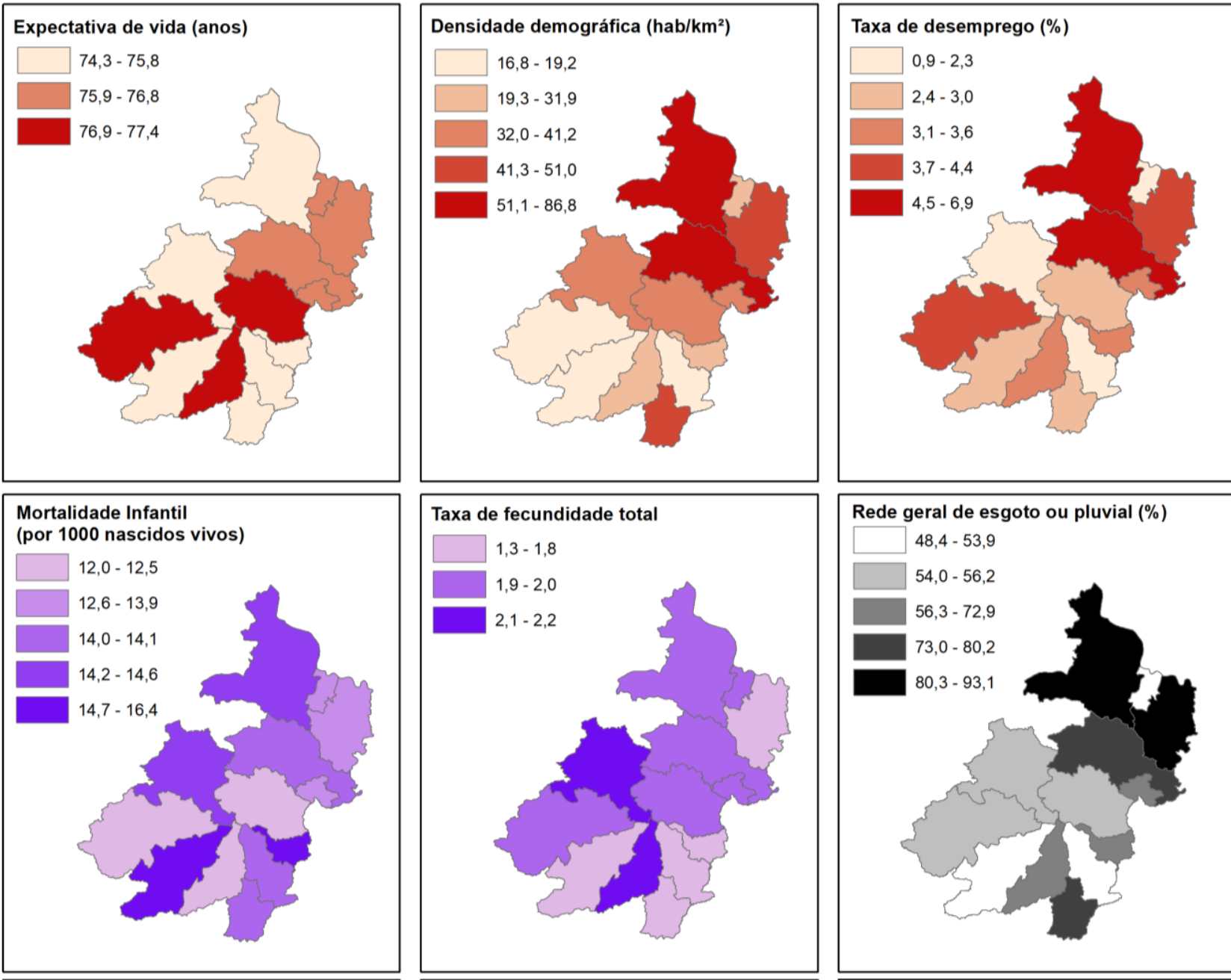

Rede geral de esgoto ou pluvial (\%)

$48,4-53,9$
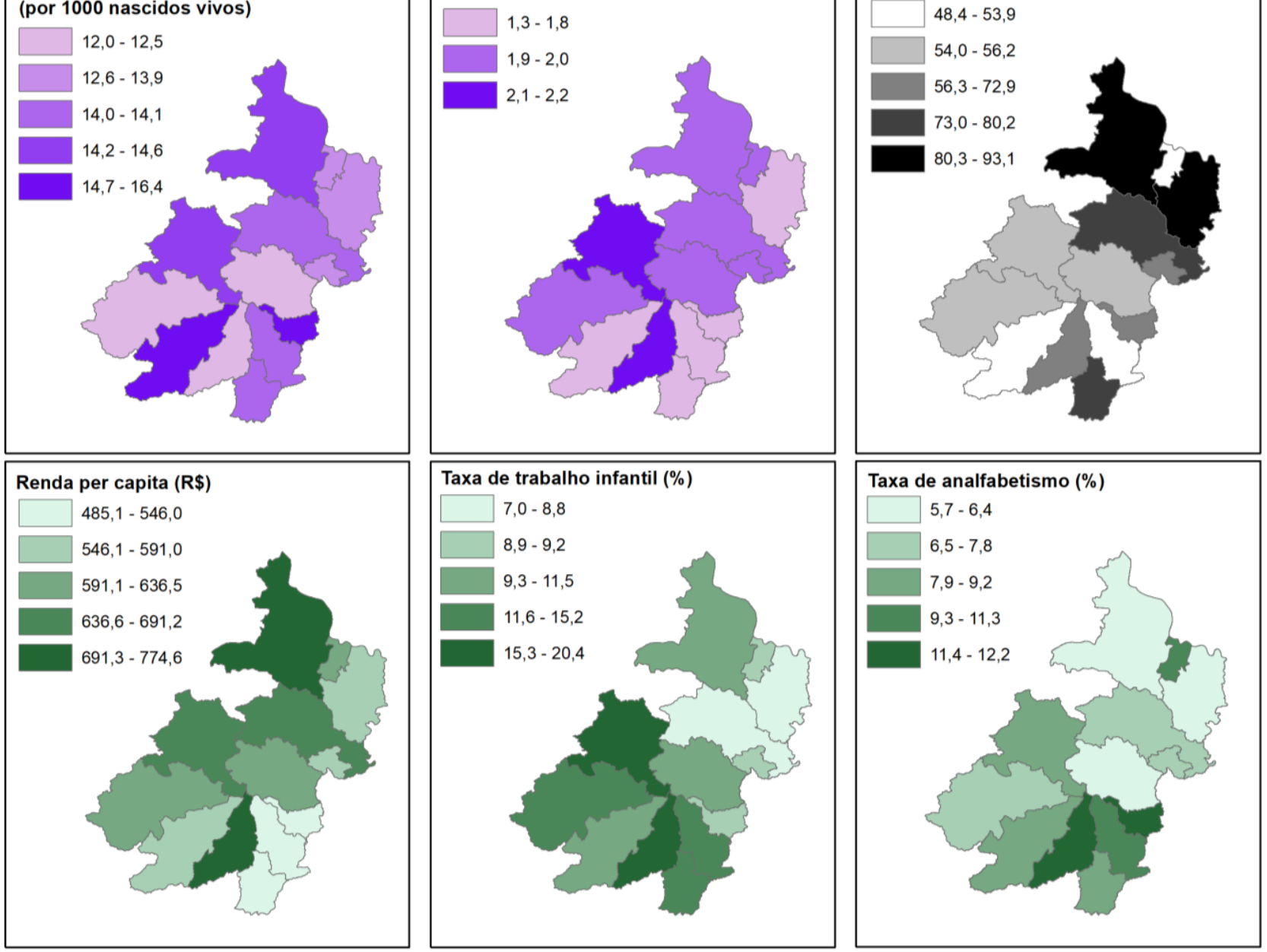

Daniel Bando; Tiago Marini

Fonte: Censo demográfico (IBGE 2010)

06/08/2018

Figura 3 - Indicadores sociodemográficos dos municípios que compõem a APA do rio Machado, 2010.

Fonte: IBGE, 2010; BANDO, 2019; MARINI, 2019. 
Considerando que a renda per capita da população é um bom indicador da disponibilidade de recursos financeiros para utilização adequada dos recursos naturais, Alfenas e Ipuiúna, em primeiro lugar, e Machado e Campestre, em segundo, por um lado, teriam maior possibilidade de diferentes segmentos de a sociedade local (sobretudo o governo municipal) investir em políticas que promovessem uma relação de maior equilíbrio entre população e os recursos naturais (sobretudo, os hídricos) pois a renda desses municípios é a mais alta no conjunto das unidades em estudo. Por outo lado, uma menor renda per capita, como se verifica nas unidades municipais mais ao sul da APA, indica haver maior necessidade de investimento e atenção do Estado nesse tipo de ação.

No que se refere à cobertura por rede geral de esgoto, Alfenas e Machado se despontam, juntamente com Congonhal, como aqueles cujas populações residentes são atendidas por esse serviço. No entanto, se se observa a taxa de analfabetismo, Ipuiúna e São João da Mata possuem as mais altas da área em questão, ou seja, mais de $11 \%$ dos habitantes dessas unidades municipais são analfabetos, condição que poderá dificultar a implementação de medidas de valorização do meio natural que os cercam, o que reforça mais uma vez a necessidade de maior atenção com a população dessas unidades. Do lado oposto, Alfenas, Paraguaçu e Poço Fundo apresentam a mais baixa taxa de analfabetismo.

\section{CONSIDERAÇÕES FINAIS}

Como vimos, o processo de formação territorial dos municípios que integram a APA do rio Machado, a partir da $2^{\mathrm{a}}$ metade do século XVIII, foi marcado por eventos que modificaram as relações sociais e aquelas estabelecidas entre a população e o espaço regional. A introdução da cafeicultura e a chegada dos trilhos em importantes cidades desses municípios, bem como a imigração de estrangeiros (sobretudo, italianos), e de outras partes do Brasil, para o trabalho naquela atividade econômica, estão entre os principais condicionantes de mudanças no ambiente natural, no qual se insere o rio Machado e seus afluentes.

Desde então, a sociedade circunscrita à área drenada pelos rios da bacia hidrográfica em foco vem passando por alterações significativas. Os municípios que compõem a APA do rio Machado possuem alta taxa de urbanização, sugerindo que os cursos d'água que atravessam ou tangenciam áreas urbanas, ou densamente povoadas, carecem de atenção e intervenção por parte dos órgãos que administram a região da bacia.

É importante destacar que nos últimos 100 (cem) anos foi criada a maioria dos municípios desse quadrante regional, sendo que a cidade de Alfenas e Machado se consolidaram como centralidades urbanas, sendo os seus municípios os mais populosos. Além desses atributos, o ambiente em estudo possui um contingente populacional feminino superior ao dos homens e todas 
as unidades municipais possuem IDHM superior à média mineira e brasileira. O percentual de jovens é significativo em todos os municípios da APA, aspecto que reforça a necessidade de discussão sobre a utilização adequada dos recursos naturais nas unidades de ensino. Desse modo, é fundamental se criar parcerias entre universidades, secretarias municipais de educação, prefeituras e o IEF (Instituto Estadual de Florestas), de maneira que a comunidade escolar seja convidada a discutir os problemas da APA do rio Machado e apresentar propostas de intervenção que melhorem a qualidade de vida dos residentes, tanto nas margens dos rios como em outras subzonas da APA.

Em termos gerais, a utilização adequada dos recursos naturais e dos recursos hídricos, em particular, não se concretizará se a população residente não dispuser das condições adequadas de vida, de moradia e de existência. Nesse sentido, torna-se necessário prover à sociedade local de trabalho e de educação de qualidade, condições fundantes para o uso adequado dos rios e consolidação da democracia na região e no País.

\section{AGRADECIMENTOS}

Os autores agradecem o apoio e subsídios fornecidos pela Agência Regional de Proteção Ambiental da Bacia do Rio Grande (ARPA), que financiou o Projeto "Diagnóstico geoambiental da APA da bacia hidrográfica do rio Machado/MG", bem como ao Instituto Estadual de Florestas (IEF) e à Universidade Federal de Alfenas (UNIFAL-MG).

\section{REFERÊNCIAS}

DAMIANI, Amélia. População e Geografia. São Paulo: Contexto, 2006.

DAVI, Rafaela do Rosário. Memórias da evolução socioespacial da cidade de Alfenas - MG, entre 1874 e 1952. Trabalho de Conclusão de Curso - Geografia (Unifal-MG), Alfenas, 2017. Disponível em: <https://www.unifal-mg.edu.br/geografia/sites/default/files/TCC\%20Rafa.pdf >. Acesso em: 06 out. 2018.

GAMBI, Thiago Fontelas Rosado et al. O processo de urbanização no sul de Minas em transição. Anais... XV Seminário Sobre Economia Mineira, Diamantina, 28 de agosto de 2012.

IBGE. Base de informações do Censo Demográfico 2010: Resultados do Universo por setor censitário. Rio de Janeiro, 2011.

. Censo demográfico (2010). Rio de Janeiro: IBGE, 2010.

MARTINS, Marcos Lobato. A marcha do café no sul de Minas, décadas de 1880-1920: Alfenas, Guaxupé, Machado e Três Pontas. In: SAES, Alexandre Macchione et al. Sul de Minas em urbanização: modernização urbana no início do século XX. São Paulo: Alameda, 2016.

Paisagens do passado no sul de Minas: os ambientes rurais regionais e sua transformação pelo avanço da cafeicultura (décadas de 1870-1920). In: SAES, Alexandre Macchione et al. Sul de Minas em urbanização: modernização urbana no início do século XX. São Paulo: Alameda, 2016. 
MARTINS, Fábio Vieira; MILAN, Valdelice Mezavila. Análise socioambiental das bacias hidrográficas urbanas do município de Machado - MG. Trabalho de Conclusão de Curso Geografia (Unifal-MG), Alfenas, 2011.

MINISTÉrio DO MEIO AMBIENTE. Plano de Manejo da APA Bacia do Rio Descoberto. Brasília, 2014.

PEREIRA, Ronildo Alcântara; BARBOSA, Maria de Fátima Nóbrega. Diagnóstico socioeconômico e ambiental de uma microbacia hidrográfica no semi-árido paraibano. Engenharia Ambiental - Espírito Santo do Pinhal, v. 6, n. 1, p. 137-153, jan/abr 2009.

PORTO, Gil Carlos Silveira. Notas sobre os impactos da construção da Rodovia Fernão Dias no espaço intraurbano de Alfenas (MG), em meados do século XX. In: XVIII Encontro Nacional de Geógrafos. São Luís, Anais... 2016.

SAES, Alexandre Macchione; CASTILHO, Fábio Francisco de Almeida. Cortando a Mantiqueira: entre café e abastecimento no sul de Minas (1880-1920). In: SAES, Alexandre Macchione et al. Sul de Minas em urbanização: modernização urbana no início do século XX. São Paulo: Alameda, 2016. 